\title{
DISTRIBUIÇÃO ESPACIAL E ARQUEOLOGIA DA PAISAGEM O Sítio Arqueológico El Socorro, um Padrão Atípico Mesoamericano
}

\section{SPATIAL DISTRIBUTION AND LANDSCAPE ARCHEOLOGY The Socorro Archaeological Site, The El Socorro Archaeological Site, an Atypical Mesoamerican Pattern}

\author{
Pedro Jiménez Lara ${ }^{1}$ \\ pejila@hotmail.com \\ Carlos Fabiano Marques de Lima² \\ cfmlimas@gmail.com
}

\section{RESUMO}

O presente texto surgiu como um desafio, a análise de um assentamento mesoamericano pré-hispânico, denominado El Socorro, localizado próximo a cidade de Tlacojalpan em Veracruz, México, região do Golfo da Mesoamerica. A realização de uma abordagem contextual dos sítios arqueológicos, numa perspectiva intra e extra sítio, num primeiro momento fazendo uso de ferramentas de geoprocessamento e de procedimentos topográficos com estação total. Optamos nesse texto utilizar como substrato para nossas observações e avaliação das imagens de satélite, desenhos topográficos e dados arqueológicos dos sítios pré-hispânicos uma abordagem centrada na arqueologia da paisagem para uma identificação em superficie mas ampla do sitio dentro do contexto regional e mesoamericano. Um analisis complexo por tratarse de um sitio excepcional pela distribuçao e forma como foi construído.

Palavras-chave: El Socorro, Mesoamérica, Sitio arqueológicos, Paisagem

\footnotetext{
${ }^{1}$ Instituto de Investigaciones Histórico Sociales, Universidad Veracruzana, Mexico

${ }^{2}$ Arqueologo free lance
} 


\begin{abstract}
The present text appeared as a challenge, the analysis of a pre-Hispanic Mesoamerican settlement, named El Socorro, located near the city of Tlacojalpan in Veracruz, Mexico. region of the Gulf of Mesoamerica. The realization of a contextual approach of archaeological sites, in an intra and extra-site perspective, at first using geoprocessing tools and topographic procedures. We chose to use as substrate for our observations and evaluation of satellite images, topographical drawings and archaeological data of the prehispanic sites, an approach centered on landscape archeology for a broader surface identification of the site within the regional and Mesoamerican context. A complex analysis because it is an exceptional site for the distribution and the way it was buil.
\end{abstract}

Keywords: El Socorro, Mesoamerica, Archaeological Site, Landscape

\title{
CONTEXTO DA PESQUISA
}

A partir do curso Introducción a Mesoamérica, ministrado na pós-graduação da Universidade Federal de Pernambuco - UFPE, surgiu a ideia de apresentar um ensaio com um tema relacionado a este grande território originário, localizado, também no continente americano.

Foi através de um conhecimento maior da arqueología mesoamericana que surgiu o interesse em se falar sobre este sitio arqueológico excepcional dentro do território mesoamericano. Mas, porque excepcional? Simplesmente porque é un espaço criado, sua estruturação é distinta, sai da típica formação conhecida como a praça mesoamericana que consiste em um espaço limitado por quatro construções, muitas das vezes com uma orientação astronómica específica. No caso do El Socorro só são duas linhas, 110 túmulos, paralelas, dividida em duas 
partes pela Laguna del Monte, criando um espaço particular com características especiais onde se desenvolvia suas atividades de produção.

Além da distância entre a mesoamérica e o território brasileiro, o presente texto surgiu como um desafio, ou seja, a análise de um assentamento mesoamericano pré-hispânico, denominado El Socorro, localizado nas proximidades da cidade de Tlacojalpan em Veracruz, México. A localização e registro deste sítio arqueológico ocorreu como resultado da cobertura e varredura de superfície realizada no âmbito do projeto "Patrón de Asentamiento y Poblamiento Prehispánico en la Cuenca Baja del Papaloapan”, dirigido pelo arqueólogo Pedro Jiménez Lara (primeiro autor deste artigo)

O objetivo da pesquisa foi a realização de uma abordagem contextual dos sítios arqueológicos, numa perspectiva intra e extra sítio, num primeiro momento fazendo uso de ferramentas de geoprocessamento e de procedimentos topográficos.

Entretanto, em outras áreas da região do Golfo, a exemplo do sítio arqueológico de Tajín, e vários outros sítios na mesoamerica foi possível identificar o inicio de uma organização espacial nas construções dos edifícios que estabelece de forma clara a delimitação dos espaços específicos das mais variadas atividades. Tal organização espacial estará presente na mesoamerica desde o período pré-clássico ao pós-clássico. 
Realizar uma análise do padrão de assentamento do sítio El Socorro é um desafio, pois o sítio não apresenta a típica distribuição espacial predominante na mesoamérica para os povoados e cidades, principalmente a ausência das praças destinadas as atividades coletivas administração, comercio, religião, etc., proposta como modelo por Castells (1980).

Optamos nesse ensaio utilizar como substrato para nossas observações e avaliação das imagens de satélite, desenhos topográficos e dados arqueológicos dos sítios pré-hispânicos uma abordagem centrada na arqueologia da paisagem apresentada e discutida em diversas bibliografias.

\section{A ARQUEOLOGIA DA PAISAGEM}

O começo do século XX foi marcado por um determinismo geográfico e uma difusão cultural clássica. (Korinman, 1990) ${ }^{1}$. As atividades efetivadas por Franz Boas e seus seguidores introduziram novos padrões de pesquisas etnográficas no estudo das interações homem/ambiente. Em sua obra The Central Eskimo (1888), Boas passou a enfatizar o papel da herança histórico-cultural dos esquimós sobre o ambiente. Para ele, ambientes semelhantes necessariamente não resultariam em semelhanças culturais. Os seguidores de Boas entenderam que o homem criava seu ambiente e não era determinado por ele. Argumento utilizado contra as limitações ambientais ao desenvolvimento cultural aplicada por Betty Meggers (1972). 
Nesse sentido as pesquisas de Julian Steward (1955) representam uma das importantes contribuições da antropologia ecológica nas pesquisas arqueológicas, principalmente na aplicação por parte da antropologia do estudo das relações entre dinâmica populacional,

Organização social e cultural das sociedades humanas no meio ambiente ao qual estão inseridos. Mesmo que a proposta de Steward (1955) tenha se tornado a base para futuras analises difusionistas aplicadas nas Américas, as possibilidades teórico-metodológicas da abordagem ecológica-cultural apresenta para o campo das pesquisas novas possibilidades de compreender as ações e escolhas humanas nas mais diversas áreas.

Assim, nos utilizamos uma abordagem ecológica para entender a dinâmica das sociedades humanas e toda sua complexidade de elementos, orgânicos e inorgânicos, como se refere Butzer (1989), que em nosso trabalho tem um papel importante quando da análise dos dados contextuais do sítio El Socorro. ${ }^{3}$

Ao trabalhar sítios arqueológicos numa perspectiva contextual buscamos enfatizar parâmetros teóricos propostos por Clarke (1978) no livro intitulado "Spatial Archaeology", aonde o autor apresenta de forma mais detalhada os estudos realizados por subsistemas sem que seja necessária uma vinculação obrigatória

\footnotetext{
${ }^{3}$ Michel Korinman, Quand l'Allemagne pensait le monde. Grandeur et décadence d'une géopolitique, Fayard, 1990.
}

Indexadores: Latindex, ISIS, Google Academic 
entre ambos. $\mathrm{O}$ autor propôs a possibilidade da acumulação de dados através de 3 níveis de abordagens: micro, semimicro e macro, assim descritos por Clarke:

"Micro - diz respeito ao interior ou centro do sítio, às estruturas interiores, abrigos, casas, cemitérios, templos, etc.”. Neste são importantes os aspectos individuais e os modelos socioculturais são mais relevantes que os estudos econômicos;

Semimicro - é aquele que compõe o conjunto das estruturas do interior do sítio e das suas relações com os arredores imediatos. Os modelos arquitetônicos e urbanísticos devem ser levados em conta, e os aspectos culturais e sociais assumem preponderância sobre os econômicos, tal como ocorre nas analises de nível micro;

Macro - diz respeito às relações do sítio com a geografia, as paisagens, os relevos, o clima e às adaptações econômicas e culturais das sociedades com estes. Esta escala envolve as questões de tempo, distância e energia despendida para exploração do meio ambiente. "Assim, os fatores econômicos predominam sobre os demais nos estudos deste nível."4.

A abordagem ambiental apresentada por Clarke (1978), em seu nível macro, e Fernandez Martinez e Ruiz Zapatero (1986), também discutida em suas possibilidades por Butzer (1989), é relevante quando no enfoque contextual o estudo dos artefatos arqueológicos deixa de ser o objetivo exclusivo da pesquisa arqueológica, o artefato pelo artefato, dando espaço para um leque de abordagens mais amplo, principalmente ao espaço externo ao sítio arqueológico.

\footnotetext{
${ }^{4}$ BARCELOS, Idem, pg. 37.
}

Indexadores: Latindex, ISIS, Google Academic 
O segundo enfoque utilizado na análise dos sítios estudados é dado pela abordagem da Arqueologia da Paisagem, Trément ${ }^{5}$ aborda o estudo da paisagem como o último estágio das atividades desenvolvidas em campo, onde os fenômenos observados devem ser inseridos num contexto mais amplo de analise. Os sítios contextualizados no ambiente passam a ser elementos de uma rede onde o ambiente e sua mobilidade é representativa e pode reconstituir os diversos momentos da paisagem. O estabelecimento do padrão de assentamento de um conjunto de sítios além de contribuir para a identificação de uma ou mais traços culturais, numa espacialidade e temporalidade determinada, favorece na montagem de um modelo de ocupação e exploração deste espaço em momentos de estabilidade e instabilidade.

As imagens da figura 1 representam as plantas de três sítios arqueológicos de diferentes regiões mesoamericanas: Oaxaca, Centro de México e Costa do Golfo. Os três apresentam a típica praça mesoamericana como uma tradição arquitetônica desta macro área cultural.

A área de localização do sítio arqueológico atualmente fica na margem direita do rio Papaloapan aproximadamente a uns $3 \mathrm{~km}$ em linha reta no sentido noroestesudeste a partir do rio, nas coordenadas $18^{\circ} 11^{\prime} 37,43^{\prime \prime} \mathrm{N}$ e $95^{\circ} 56^{\prime} 6,68^{\prime \prime} \mathrm{O}$.

\footnotetext{
${ }^{5}$ TRÉMENT, F (2000). Le programme "Histoire de l'occupation du sol et e'volution des paysages dans le basin de Clermont-Ferrand" - Archéologie spatiale et archéologie du paysage. Revue D’Auvergne - Nouvelles Archéologiques du terrain au laboratoire, pg. 111 - 127.
} 

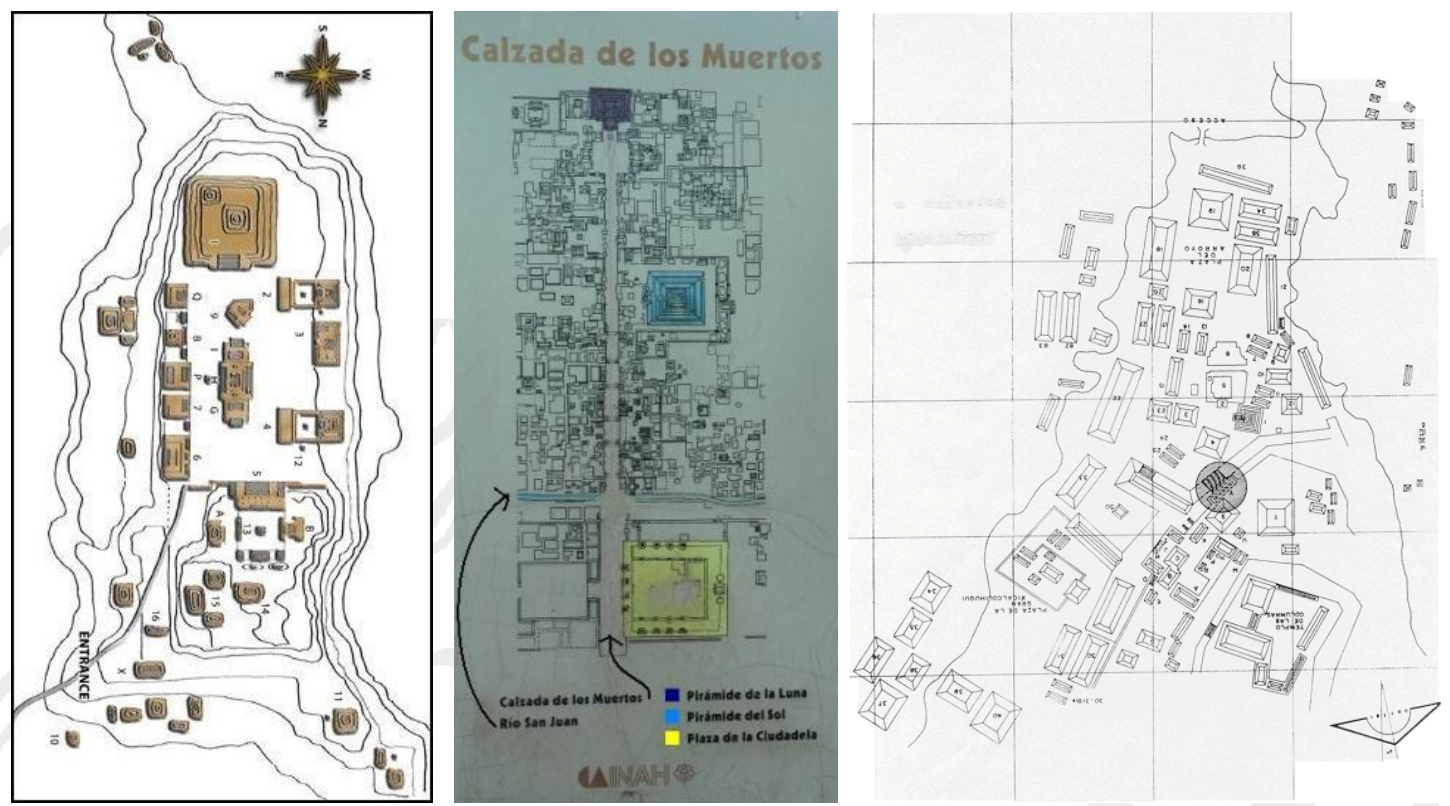

Figura 1. Plantas dos sítios Monte Albán, Teotihuacan e Tajín.

\section{SÍTIO ARQUEOLÓGICO EL SOCORRO}

Numa análise regional a área de inserção do sítio Socorro corresponde a "Cuenca Baja do rio Papaloapan", segundo as informações de Jiménez "La cuenca baja del Papaloapan abarca uma superfície de $12.000 \mathrm{Km}{ }^{\text {’2 }}$. A presença da água é extremamente abundante nesta região como podemos observar através da rede hidrográfica em imagens de satélite, onde podemos perceber: rios, lagos, áreas alagadas e pântanos. Como os elementos geográficos tiveram uma importância relevante no cotidiano das populações mesoamericanas, pensamos que no caso 
especifico do sítio Socorro Blanco a dinâmica do rio Papaloapan pode explicar a especificidade de sua distribuição espacial.

Dentro do universo de sítios pesquisados na área onde estão incluídos os sítios Las Piñas, El Zapote, La Carmela, San Francisco, Palmira e El Panteon. Todos guardam a mesma composição mesoamericana: espaço limitado por quatro construções.

O processo de ocupação da região de inserção do sítio Socorro corresponde a uma área de convergências e presença de diferentes culturas representadas pelos Huastecos, Totonacos e Olmecas. A diversidade cultural mesoamericana apresenta a mesma intensidade que tem os diferentes ambientes ecológicos mesoamericanos.

A partir do período Pré-Clássico 2.500 anos a.C. é percebido o início de uma organização espacial mais ordenada, depois das ocupações, através da segregação de espaços destinados a atividades especificas de um grupo (comerciantes, sacerdotes, etc.) e coletivas. Nesse momento elementos geográficos serão incorporados nas escolhas de implantação, construção e expansão das “cidades".

A diversidade étnica presente na Mesoamérica e também na região do rio Papaloapan foi bem representada através de uma densidade demográfica relevante 
para o período Clássico e Pós-Clássico, com cidades como Cempoala com uma população de 20 mil a 30 mil vizinhos. $^{6}$

Mesmo cidades menores seguiram certo padrão de organização dos espaços privados e públicos (comerciais ou residenciais), que foram sistematizados por Castells (1974, apud Jiménez, 2003), sendo possível identificar nas diversas cidades mesoamericanas a seguinte estrutura: gestão/administração, produção, intercâmbio, consumo e religião.
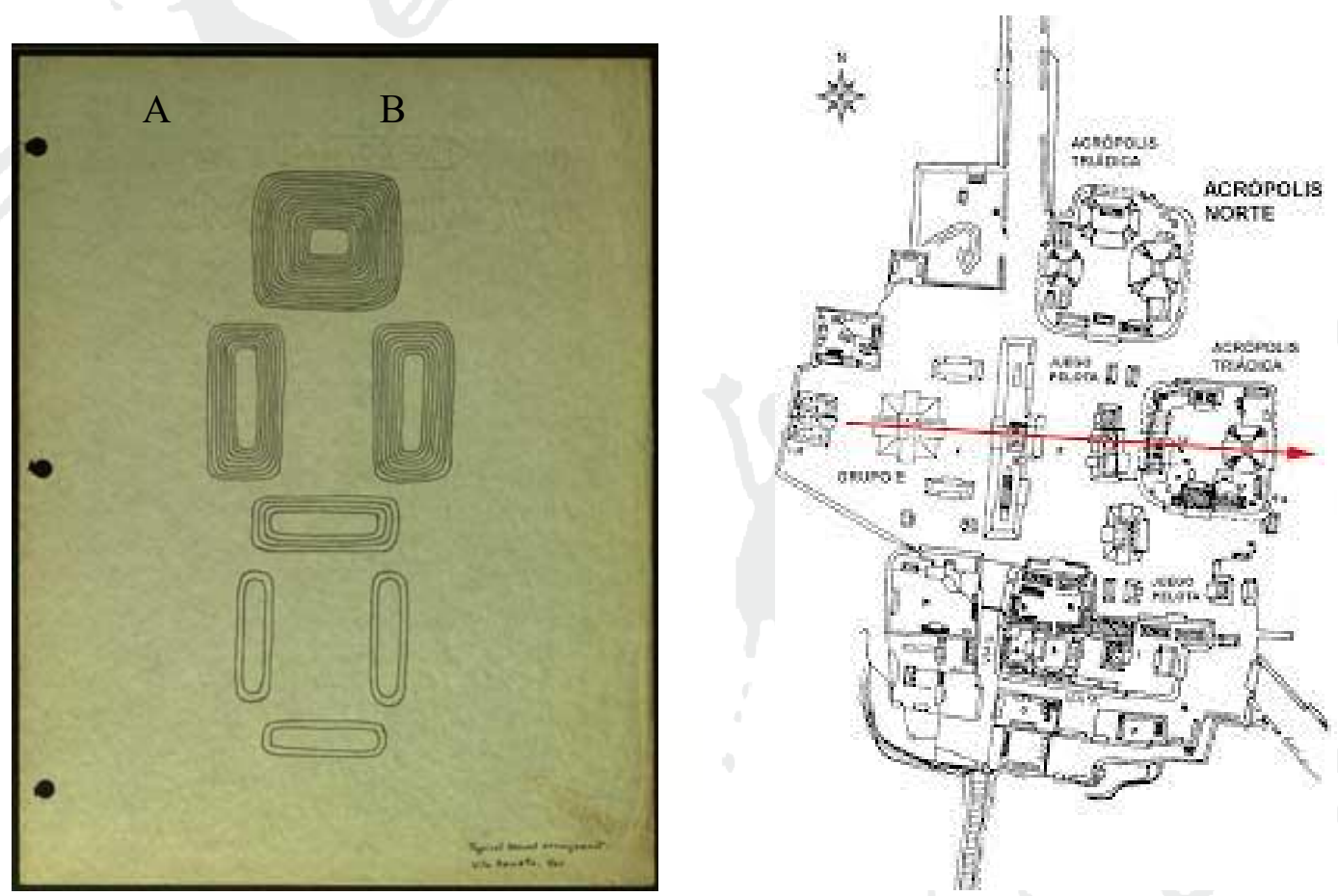

Figura 2. A - Desenho de planta básica de distribuição das construções.

\footnotetext{
${ }^{6}$ Fray J. de Torquemada, op. cit., p. 251.
} 
Podemos ver o desenho de planta básica de distribuição das construções em alguns dos sítios de território mesoamericano, neste caso se trata de Yaxhá em Guatemala (Figura no. 2) poucos casos apresentam triadas, é dizer, três construções e uma tendo um rol particular entre os dois espaços.

Sítios arqueológicos como Monte Alban, Tajín, Teotihuacan, Las Choapas, são expoentes da organização das cidades mesoamericanas e da dinâmica de ocupação espacial nas relações entre construções-áreas-funções que irão nortear as escolhas topográficas e da paisagem para a implementação das cidades. Anexos.

Mesmo que as cidades mesoamericanas não apresentassem um projeto urbanístico como a proposta do modelo de Castells (1974) bem definido com acessos padronizados e bem distribuídos, praças dispostas de forma sistemática, a não implementação desse traçado urbanístico não impediu que esses elementos estivessem presentes em todas as cidades pré-hispânicas numa delimitação quadrangular do espaço urbano. Mesmo as construções destinadas a grupos hierarquicamente superiores nas sociedades pré-hispânicas foram cercadas por amplos espaços públicos, praças, onde os resultados das diversas atividades religiosas, administrativas, comerciais eram coletivizados.

Contudo, a partir do projeto de identificação dos padrões de assentamento na Cuenca Baja do rio Papaloapan, o sítio El Socorro, após levantamento de prospecção de superfície e topográfico, diverge completamente dos elementos 
arquitetônicos e elementos utilizados que compõem as construções das cidades pré-hispânicas.

Os padrões arquitetônicos pré-hispânicos apresentam: montículos residenciais, montículos cônicos e alongados, grandes plataformas de quatro lados, etc. Muitas vezes esses montículos delimitavam através dos pontos cardais os espaços públicos e os montículos cônicos associados a outros alongados formando muitas vezes a letra " $T$ " delimitavam as áreas sagradas para a realização o Jogo de Pelota.

A presença dos montículos delimitadores dos espaços coletivos e restritos também faz parte dos elementos construídos no sítio, porém, a distribuição espacial dessas unidades construtivas numa disposição linear não corresponde ao traçado esperado para uma cidade pré-hispânica, onde era elemento de relevante importância o estabelecimento de áreas funcionais segregadas por elementos arquitetônicos ou naturais (rios, riachos), o que não ocorre em El Socorro, onde os montículos estão dispostos em linha a partir de uma pequena lagoa e ao longo de um canal.

Assim, pensamos que a dinâmica do sistema hídrico foi elemento delimitador das escolhas realizadas no processo de disposição dos montículos na área. Sendo o sujeito mais importante nessa relação entre o ambiente natural e cultural o rio Papaloapan. 


\section{ESPACIALIDADE DOS MONTÍCULOS DO SÍTIO EL SOCORRO}

No momento de realizar a análise do tipo de assentamento ocorrido no sítio arqueológico, percebemos que também uma analise da toponímia local lançou novos elementos que fortalecem a perspectiva de que a presença abundante de água foi um impulsionador bastante forte nas formas de ocupar a área.

Numa primeira análise das imagens de satélite percebemos que o principal curso de água, o rio Papaloapan o das mariposas, dista atualmente do sítio arqueológico $3 \mathrm{~km}$, porém em observações mais detalhadas dos elementos geomorfológicos da região identificamos que o curso do rio em períodos antigos percorria outros locais, não seria errado avaliar que foram inúmeras as mudanças de seu curso, tendo esse rio um histórico muito intenso de migrações de sua passagem na região. Porém, vamos agora focar nossa atenção na toponímia da área, em dois nomes bastante explicativos para se entender como a dinâmica hidrológica marcou a vida das populações.

A toponímia pode ser vista como um importante caminho de reconhecimento indireto do território trabalho nas pesquisas que buscam dados contextualizados para os sítios arqueológicos. Dados que representem possibilidades de interpretações para as informações representadas pelo próprio sítio, enquanto unidade espacial, e pelos vestígios encontrados em seu interior. 


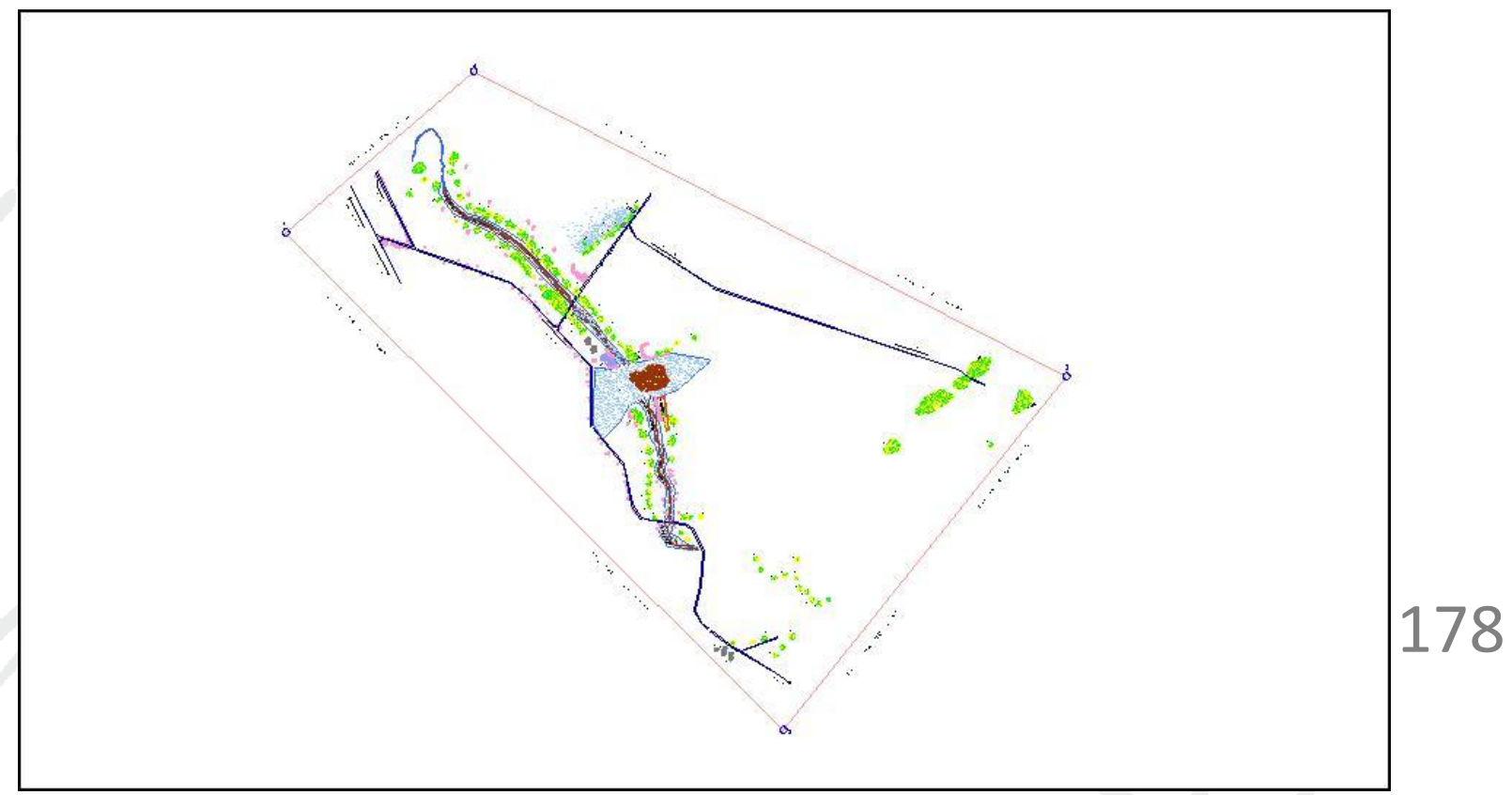

Figura 3. Levantamento topográfico do sítio El Socorro (Jimenez, 2002).

Para a área de inserção do sítio El Socorro, temos três nomes extremamente importantes, o nome do rio Papaloapan, da cidade de Tlacojalpan e da cidade de Chacaltianguis, nomes derivados da língua Nahuatl que significam Rio das Mariposas, Entre Águas e Areias, Mercado de Camarões, respectivamente.

A construção do nome Papaloapan nos remete a um momento da conquista para uma região de pântanos, bacia do rio Papaloapan e os nomes Tlacojalpan e 
Chacaltianguis estão sempre se remetendo direta ou indiretamente a vivência e exploração da água.

Quando começamos a pensar quais os motivos para os montículos de Socorro, terem sido dispostos de forma linear, entendemos que a primeira questão seria não pensar o sítio arqueológico como a construção de uma cidade pré-hispânica como foi proposto através do modelo Teorico de Castells (1974). A permanência nessa forma de tentar entender o sítio não lograria frutos positivos.

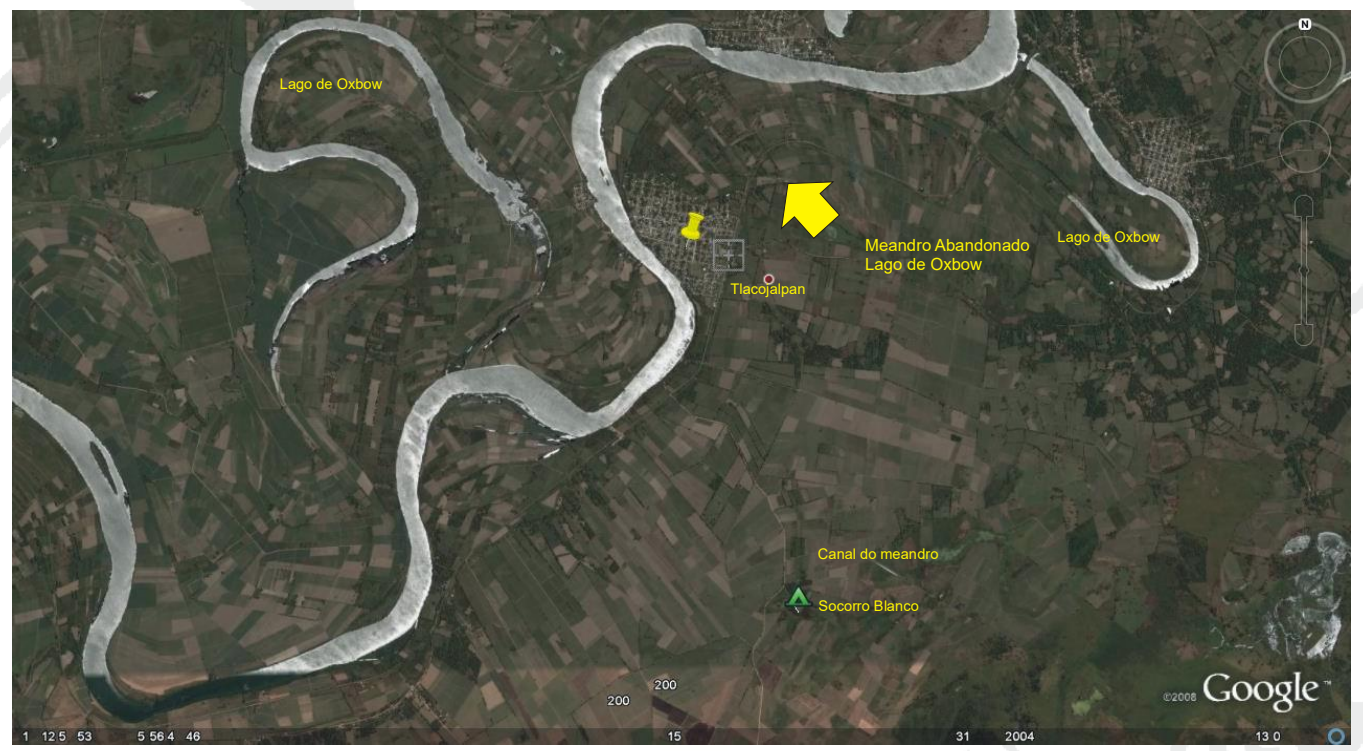

Figura 4. Imagem de satélite com a identificação dos meandros.

Uma hipótese que começamos a trabalhar era que os montículos foram dispostos em linhas paralelas com um canal artificial construído em direções opostas 
utilizando-se da pequena lagoa existente. Percebemos que fizemos uma avaliação equivocada sobre o canal artificial.

O que pensávamos ser natural não o era. O canal que separa os montículos do sítio arqueológico faz parte de um antigo meandro abandonado pelo rio Papaloapan. Anteriormente nos referimos à intensa dinâmica de alteração de curso deste rio. Após dias de avaliação das imagens de satélite disponíveis, Google Earth, de alguns dados geomorfológicos para a região e toponímia, percebemos que a área apresenta ambientes ecológicos distintos: terras secas, áreas de inundação e pântanos, (Figura no. 4)

Através das imagens podemos identificar uma elevada quantidade de meandros abandonados pelo rio, muitos em processo de sedimentação ou já sedimentados e que durante o processo de abandono foram transformados em lagos de oxbow.

Com esses dados preliminares, percebemos que a atual lagoa é apenas o que restou de um imenso meandro abandonado e transformado em lago de oxbow, que foi utilizado para atividades econômicas, possivelmente ligadas à fauna aquática num ambiente mais controlado. Atualmente o meandro que formava o lago vem sendo progressivamente sedimentado, exemplificado pela descontinuidade de seu canal na direção norte do sítio, o que dificultou nossas primeiras observações e hipóteses incorretas quanto à artificialidade do canal. 
Propomos as seguintes hipóteses de trabalho para se estudar o sítio arqueológico, que: 1. El Socorro foi uma cidade com atividades de produção especifica nos moldes arquitetônicos já identificados para tal; 2. O canal que separa as linhas de montículos faz parte de um lago de oxbow.

\section{CONCLUSÃO}

Nos resultados das prospecções de superfície realizadas na região além do sítio El Socorro, outros seis sítios arqueológicos, já citados, foram identificados e registrados na área.

Se existia uma hierarquia horizontal na distribuição espacial interna das cidades no Golfo do México, pensamos que essa mesma hierarquização foi estabelecida entre o sítio El Socorro e os demais sítios registrados na região. Provavelmente as populações exploraram de forma intensiva e extensiva os recursos hídricos da área. Se a toponímia de Chacaltianguis faz menção a um mercado de camarão, possivelmente El Socorro, dentro da hierarquia de sítios, foi utilizado como local destinado exclusivamente para a produção e exploração de camarão no canal do lago de Oxbow. A presença de água nesse longo canal num ambiente sem energia poderia dar suporte à divisão de tanques destinados a criação dos camarões para o comércio. Assim especificado no codex Matricula de Tributos

Porém, pensamos ser fundamental a correlação de dados cronoestratigráficos do sítio, do lago de oxbow e do aparecimento da atual lagoa. 


\section{REFERENCIAS BIBLIOGRÁFICAS}

ALAGÓN LASTE, José María (2014). “¿Viviendas aisladas o núcleos urbanos? Modelos urbanísticos del Instituto Nacional de Colonización en Aragón: la zona de MonegrosFlumen (Huesca)". Norba. Revista de Arte. XXXIV: 221-247.

ALMANDOZ, Arturo (1993): "Consideraciones conceptuales sobre Urbanismo", en Revista Ciudad y Territorio, Estudios Territoriales, Vol. 1, $3^{\mathrm{a}}$ época, Edit. MOPT, España 1993.

BARCELOS, Artur H. F. (2000). Espaço e Arqueologia nas Missões Jesuítas: o caso de São João Batista. Porto Alegre: EDIPUCRS, Coleção Arqueologia 7.

BOVILlE, Belén; Sánchez-González, Diego (2007). Planificación Territorial y Desarrollo Sostenible en México, Perspectiva Comparada / Planning and Sustainable Development in Mexico, Comparative Perspective. Universidad de BarcelonaUniversidad Autónoma de Tamaulipas. p. 465. ISBN 978-84-611-9500-8.

BOAS, Franz (n. d.), "The Relation of Darwin to Anthropology" («La relación de Darwin y la antropología») notes for a lecture; Boas papers (B/B61.5) American Philosophical Society, Philadelphia. Published on line with Herbert Lewis $2001 \mathrm{~b}$.

BUTZER, Karl W (1989). Arqueología - una ecología del hombre: método y teoría para um enfoque contextual. Barcelona: Ediciones Bellaterra, p.345.

CASTELLS, Manuel (1974)La cuestión urbana. Siglo Veintiuno de España Editores, S.A. Publicado originalmente en francés en 1972 (La Question Urbaine). Primera edición en español, .

CLARKE, David L (1978). Analytical archaeology. London: Methuen \& Co Ltd.

(1977). Spatial Archaeology. London: Academic Press.

ESPAÑOL J.: (2001) El orden frágil de la arquitectura, Fundación Caja de Arquitectos, (Arquíthesis ; 9), Barcelona, 215 pp. 
JIMENEZ Lara, Pedro (1998). Proyecto "Patrón de asentamiento y Poblamiento Prehistórico em la Cuenca Baja del Papaloapan. Vera Cruz: Universidade de Vera Cruz/Conacyt.

Trabajo, Xalapa, Vera Cruz.

(2003). Arquitectura y poder en El Tajín. Cuadernos de

MEGGERS, Betty J. 1972a. Prehistoric America. Aldine-Atherton, Chicago and New York. VII +200 pp., 100 figs.

PILLET CAPDEPÓN, F. (2004) La geografía y las distintas acepciones del espacio geográfico. Investigaciones geográficas, , $\mathrm{N}^{\circ} 34$, p. 141-154.

RUIZ Cabañas, José Angel. (2008) El Socorro un complejo resiedencial prehipsanico en la Cuenca del "Papaloapan, Municipio del Tlacojalpan, Ver. Tesis de Licenciatura, Universidad Veracruzana, Xalapa, Ver., México.

SÁNCHEZ-GONZÁLEZ, Diego; Ledezma-Elizondo, María Teresa; Rivera-Herrera, Nora Livia (2011). Geografía Humana y crisis urbana en México / Human Geography and urban crisis in Mexico. Monterrey: Universidad Autónoma de Nuevo León. p. 278. ISBN 978-607-433-688-7.

SÁNCHEZ-GONZÁLEZ, Diego. «Aproximaciones a los conflictos sociales y propuestas sostenibles de urbanismo y ordenación del territorio en México / Approaches to Social Conflicts and Sustainable Proposals for Urban and Regional Planning in Mexico». Revista de Estudios Sociales (42): 40-56. ISSN 0123-885X.

SCARBOROUGH, V. L., Becher, M. E., Baker, J. L., Harris, G., and Valdez, F. Jr. (1995). Water and land at theancient Maya community of La Milpa. Latin American Antiquity 62: 98-119.

SCHACHT, R. M. (1984). The contemporaneity problem. American Antiquity 49: 678695.

STEWARD, Julian H., (1955). Theory of Culture Changes, University of Illinois Press, Urbana, 1955. http//:www.ciesas.edu.mx/Publicaciones/Clasicos/Index.html. 
TILLEY, C. (1994). A Phenomenology of Landscape: Places, Paths. and Monuments, Berg, Oxford. Tilley, C.(1996). The power of rocks: Topography and monument construction on the Bodmin Moor. World Archaeology 28: 161-176.

TRÉMENT, F (2000). Le programme "Histoire de 1'occupation du sol et e'volution des paysages dans le basin de Clermont-Ferrand" - Archéologie spatiale et archéologie du paysage. Revue D'Auvergne - Nouvelles Archéologiques du terrain au laboratoire, pg. $111-127$.

TORQUEMADA, Fray Juan de, Monarquía indiana. (1986) ed. Introd. de Miguel León Portilla. México, Porrúa, 6a.EDICION. (Biblioteca Porrúa, 41, 42 y 43

GONZALO Ruiz-Zapatero (1986), Metodología para la investigación en... (PDF Download Available).https://www.researchgate.net/.../263441975 Metodología para la investigación en Full-Text Paper (PDF): Metodología para la investigación en Arqueología territorial. Cite This Publication. at Complutens de University of Madrid Gonzalo Ruiz.

VILLAFAÑEZ Emilio Alejandro, (2011) Revista de Geografía Norte Grande, 50: 135150135 Otros temas Entre la geografía y la arqueología: el espacio como objeto y representación. 